\title{
Application of cane molasses as concrete retarder admixture
}

\author{
Yohannes Kassa ${ }^{1}$
}

Received: 9 August 2019 / Accepted: 31 October 2019 / Published online: 5 November 2019

(c) Springer Nature Switzerland AG 2019

\begin{abstract}
Cane molasses a local material, one of the four types of sugar by-product coming out of the factory among with bagasse, pressed mud, and discharging water containing mud. It contains sugar, non-sugar, and water. Despite the objective of sugar factories, which intended to produce molasses whose purity is as low as possible, most of the time it contains some amount of sugar which can be capable of acting as a retarder admixture. In Ethiopia, a considerable amount of molasses is being discharged as a by-product from sugar factories every year. Thus, this study aims to explore the potentiality of molasses material for concrete works. This study tried to establish a different mix ratio of molasses as a retarder for the concrete mix, while at the same time, the properties of C-25 Concrete were determined. It was found out that the presence of molasses in concrete had significantly extended the setting time and reduce the rate of strength development at early ages but enhance the compressive strength at the later ages. During the study, it became evident that the addition of molasses into cement paste has the capability to delay the setting time of cement paste with a minimum of 380 min and a maximum of $990 \mathrm{~min}$ and at the same time it increases the concrete compressive strength at the 28th days with a range of $4.5-16.52 \%$. Therefore, molasses could be used as a conventional retarder admixture for concrete.
\end{abstract}

Keywords Molasses $\cdot$ Retarder $\cdot$ Cement concrete $\cdot$ Workability $\cdot$ Compressive strengths

\section{Introduction}

Due to the sensitive nature of chemical admixture dosages and the scarcity of expertise which could control the optimum amount of the chemical admixtures to be added in concrete products that make the applications of concrete admixture difficult in construction projects which take place in a country like Ethiopia. The challenge becomes worse when the cost to obtain chemical admixtures is taken into consideration. Thus, it is required to develop a way that aimed to utilize concrete admixture from local organic materials or industrial by-products to achieve a comparable product with a smaller cost and lesser complex procedure than chemical admixture.

Among organic chemicals, sugar is a moderate retarder. Nevil in 2006 [1] in his book suggests that the presence of retarder in concrete could produce a denser $\mathrm{C}-\mathrm{S}-\mathrm{H}$ (calcium-silicate-hydrate) product in the later age of concrete (beyond 28 days) when it is compared with concrete without retarder admixture. Alternatively, the retarded concrete obtains a reduced compressive strength during its early ages (up to 7 days). Similarly, sugar possesses the retarding effect by inhibiting the formation of hydration product, which possibly contributes to strength development [2-5].

However, contrasting views have been observed from different researchers; the retarding action of sugar mainly depends on its amount in the concrete and the chemical composition of cement $[6,7]$.

Khan and Baradan [8] study has found out that sugar has a retarding capability on the setting time of concrete. The study was conducted by comparing the effect of sugar on three different cement type with varying curing conditions, and in all cases, the setting times

$\triangle$ Yohannes Kassa, jokg12@gmail.com; wu@ethionet.et | 'Departement of Construction Technology and Management, Wollega University, Nekemte, Ethiopia. 
were extended, $0.04 \%$ (of the weight of cement) quantity of sugar has been extended the final setting time of cement past by $255 \mathrm{~min}$ that could be qualified as a common retarder.

Oyekan [9] worked on the utilization of admixture to enhance the compressive strength of sandcrete blocks by the addition of sugar. The study revealed that $0.1 \%$ sugar content (by weight of cement) increased the compressive strength of the blocks by nearly $17 \%$ at 28 days. At $0.2 \%$ sugar content (by weight of cement), the 28 days strength of the blocks was increased by only $9 \%$, but the 14 days strength of the blocks was increased by $56.6 \%$. Such quantities of sugar can, therefore, be used as a quick solution during an unexpected stoppage of mixers to avoid hardness of concrete [10].

Given the fact that Ethiopia has made a substantial investment to increase the sugar production capacity and its vision to become the world $8^{\text {th }}$ largest sugar producer by 2023 with production estimate of 4.2 million metric ton (MMT), following Australia (4.8 MMT) and preceding the USA (3. 3MMT) indicates that the production of molasses will grow proportionally [11]. In 2001-2010, the Ethiopian sugar cooperation had a production trend of 16,386 ton of molasses per annual from three sugar factories, namely Fincha, Methara, and Wenji [12]. A portion of the molasses produced in Ethiopia is used to prepare cattle feed, ethanol production, and local asphalt pavement materials. However, the amount of molasses disposed of by the sugar factories sooner or later will become an environmental threat to the country unless recycled or reused for other purposes [13].

Regardless of the goal of the sugar manufacturing unit to withdraw molasses whose purity is as little as viable, however, most of the time it incorporates sugar [14]; hence, molasses can behave as retarder as sugar did. Molasses composed of reducing and non-reducing sugars [15]. Sucrose and raffinose are the type of non-reducing sugar that exists in molasses, which has an excellent retarding capability [4]. Therefore, it is a reasonable move to put it forward the idea of using molasses as a retarder admixture as far as the amount of sugar required to get the retarding effect present in higher proportion in molasses material [16].

Neville [1] states the use of molasses as a retarder historically rooted from the early 1990s in the construction of England-France channel to prevent the setting of residual concrete.

High-performance concrete was prepared with molasses of different dosages and also found that the addition of molasses causes a considerable increase in the setting time [17].

In another experiment [18], it was found that the usage of molasses as a retarder admixture satisfies the
ASTM standard and by reducing the dosage, and it could be used as a "type A" admixture as per ASTM C494 [19] standard.

Molasses has shown a proportional result on the setting behavior of cement, slump, and compressive strength of concrete compared to VZ4 (retarder with high plasticizing effect), a commercial admixture [20].

Akar [21] promotes the application of organic admixture (molasses) in concrete by asserting the benefit with respect to cost and environmental conservation by examining its effect on concrete durability, and the use of molasses as retarder admixture could contribute to environmental preservation by converting sugar industry waste into a usable element and by reducing the demand for chemical admixture and its related by-product waste.

It is difficult to predict the properties of cane molasses collectively since properties of molasses are highly influenced by the type of the soil on which the source cane has grown, the type, and condition of the cane, climatic condition, and processing of the cane [22]. Therefore, a proper investigation of the effect of typical molasses material is necessary.

\section{Materials}

\subsection{Molasses}

The end by-product of the processing in the sugar factories, Type $C$ [23] molasses with the high solid content sample was collected from Wenji shewa sugar factory, located in Ethiopia at 110 kilometers distance from the capital city. The total molasses produced per day is approximately 189.65 tonne. Samples were extracted from the blackstrap molasses storage container. To avoid spoil and contamination due to atmospheric air and water, the molasses transported by covering with plastic containers. The physicochemical property of the molasses used throughout the experiment is reported in Table 1.

Table 1 Physicochemical characterization of molasses

\begin{tabular}{ll}
\hline Parameters & Values \\
\hline $\mathrm{PH}$ & 5.05 \\
Ash content (\%) & 10.8 \\
Brix & 79.5 \\
Color & Dark brown \\
Viscosity & $3042 \mathrm{cP} @ 20^{\circ} \mathrm{C}$ \\
Total sugar (\%) & $46.8 \pm 0.37$ \\
Free reducing sugar (\%) & $15.9 \pm 1.07$ \\
Nitrogen (\%) & $0.33 \pm 0.04$ \\
\hline
\end{tabular}




\subsection{Cement}

Commercially available ordinary Portland cement with 42.5 R Strength Class was used. The chemical composition of the cement used in this study is given in Table 2.

\subsection{Aggregate}

Locally available natural sand with absorption of $1 \%$ and moisture content of $2 \%$ as fine aggregate was used in the overall study. Crushed aggregate available from a local source has been used with a nominal maximum size of $38 \mathrm{~mm}$ with $1.5 \%$ absorption capacity and moisture content of $1 \%$ used as coarse aggregate.

\subsection{Water}

Potable water was used to mix the concrete and start the hydration reaction.

\section{Methods}

An experimental approach was implemented in order to study the suitability of molasses as concrete retarder admixture. Various concrete tests were used to investigate the retarding capability of molasses and its effect on the performance of the concrete in its fresh and hardened phase, such as consistency, workability, and strength. The tests were conducted on concrete by adding molasses at a different dosage.

\subsection{Tests on fresh concrete properties}

Under this phase, experiment was done on the consistency and setting time of cement paste and workability of concrete. Eight cement samples for consistency and setting time test and four cement samples for workability test were prepared with and without molasses. The number of replicates for each test was three.

The Vicat method, specified by ASTM C187-16 [24], was used to determine the quantity of water needed to

Table 2 National cement chemical composition produce a cement paste of standard consistency and also for the setting times of the cement samples.

The Vicat method also used for the determination of the initial and final setting time of the cement by Vicat apparatus which comply with the ASTM C 191-13 [25] specification. Here, the cement pastes were prepared by using a uniform quantity of water recorded for the standard consistence. Cement paste with varying dosage of molasses; $0.0 \%, 0.025 \%, 0.05 \%, 0.075 \%, 0.1 \%, 0.15 \%$, $0.2 \%$, and $0.3 \%$, by weight of cement was prepared. The result of the setting time is presented as a percentage change between the various molasses dosages and the control mix by using the following equation:

Percentage Increase of time setting $=\frac{\mathrm{ST}_{M}-\mathrm{ST}_{C}}{\mathrm{ST}_{C}}$

where: $\mathrm{ST}_{M}=$ Setting time of cement paste with different molasses range. $S T_{C}=$ Setting time of control cement paste.

Slump test prescribed by ASTM C 143-10 [26] was used to determine the workability of four concrete samples prepared with molasses dosage of $0.0 \%, 0.05 \%, 0.075 \%$, and $0.1 \%$ of the weight of cement. The concrete sample was taken from fresh concrete, batched and mixed to test the compressive strength of the same molasses dosage.

\subsection{Test on harden concrete properties}

After identifying the properties of the constituent materials for concrete, a theoretical mix design with targeted slump value of $25-50 \mathrm{~mm}$ and compressive strength $25 \mathrm{MPa}$ was arranged according to the EBCS [27] mix design method. Based on the theoretical mix design, a trial mix was prepared to extrapolate with the actual result, and the result was conforming to the theoretical one. Therefore, the mix design was applied for the entire concrete samples with and without molasses. The mixes were proportioned for a cement content of $352.2 \mathrm{~kg} / \mathrm{m}^{3}$, fine aggregate content of $606.2 \mathrm{~kg} / \mathrm{m}^{3}$, coarse aggregate content of $1204.66 \mathrm{~kg} / \mathrm{m}^{3}$, and water-cement ratio of 0.46 . Four concrete cube samples with the dimensions of $15 \times 15 \times 15 \mathrm{~cm}$ were prepared to determine the effect of varying dosage of molasses ranging from 0 to $1 \%$ by weight of cement. The mixtures were labeled as MC-0, MC-0.05, MC-0.075, and MC- 1 with different molasses dosage as percentages of the weight of cement represented by the numerical. Table 3 shows the final mix proportions for $1 \mathrm{~m}^{3}$ of concrete with a varying dosage of molasses.

The strength development of the concrete mix with respect to the age of mix was determined by comparing 
Table 3 Mix proportion for the concrete work

\begin{tabular}{llllllll}
\hline Mix code & Cement type & $\begin{array}{l}\text { Cement quantity } \\
\left(\mathrm{kg} / \mathrm{m}^{3}\right)\end{array}$ & W/B & Water $\left(\mathrm{kg} / \mathrm{m}^{3}\right)$ & FA $\left(\mathrm{kg} / \mathrm{m}^{3}\right)$ & CA $\left(\mathrm{kg} / \mathrm{m}^{3}\right)$ & Molasses $\left(\mathrm{g} / \mathrm{m}^{3}\right)$ \\
\hline MC-0 & OPC & 352.2 & 0.46 & 162 & 606.2 & 1204.66 & 0 \\
MC-0.05 & OPC & 352.2 & 0.46 & 162 & 606.2 & 1204.66 & 176.1 \\
MC-0.075 & OPC & 352.2 & 0.46 & 162 & 606.2 & 1204.66 & 264.15 \\
MC-0.1 & OPC & 352.2 & 0.46 & 162 & 606.2 & 1204.66 & 352.2 \\
\hline
\end{tabular}

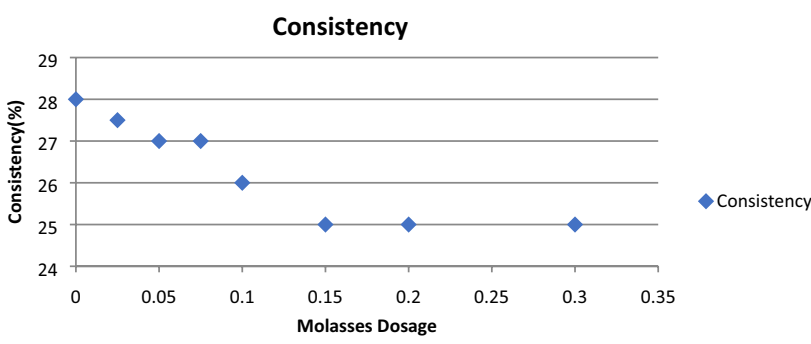

Fig. 1 Consistency result

the percentage of strength gain at 7, 14, and 28 days. Three samples were used for each age mix, and the average result adopted as the compressive strength. The test was performed according to IS 516-59 [28].

\section{Result and discussion}

The control paste (without molasses) had a normal consistency of $28 \%$. All of the pastes containing molasses showed normal consistency less than the control paste (see Fig. 1). Further increment of molasses dosage shows a continuous reduction in the water demand. The cement pastes with molasses up to $0.15 \%$ showed consistency within this range; however, beyond $0.15 \%$ addition, the results showed slightly lower values. Based on the finding, the minimum consistency was recorded for $0.3 \%$. It is evident from the result that the addition of molasses to a cement paste increases its flowability. This effect can be exploited to reduce the amount of water in a mix to increase the strength of cement paste.

The observed values of the initial and final setting time of the cement pastes for the varying dosages of molasses are given against time in Table 4.

Figure 2 shows the percentage change in the initial and final setting time of cement samples with varying degree of molasses. The highest percentage increase in setting time from the control mix was recorded for molasses range of [0.075-0.1\%], while the smallest percentage change recorded for $0.3 \%$ molasses dosage, indeed the fastest setting time attainment. According to the percentage
Table 4 Setting time record

\begin{tabular}{lll}
\hline Samples (\%) & Initial setting time (mins) & $\begin{array}{l}\text { Final setting } \\
\text { time (mins) }\end{array}$ \\
\hline 0.000 & 180 & 290 \\
0.025 & 255 & 380 \\
0.050 & 300 & 575 \\
0.075 & 525 & 930 \\
0.100 & 600 & 990 \\
0.150 & 496 & 690 \\
0.200 & 160 & 240 \\
0.300 & 75 & 150 \\
\hline
\end{tabular}

change result (by Eq. 1), minimum addition of molasses says $0.025 \%$ by weight of dry cement into concrete can increase the initial setting time with $42 \%$. The percentage increment of the final setting time is proportional to the percentage increment of the initial setting time. Maximum percentage increment is obtained with $0.1 \%$, while $0.025 \%$ was recorded for the minimum. Higher result of initial and final setting time can be achieved with the addition of a smaller amount of molasses, and this explained by the fact that the molasses used for this research contain a higher amount of sugar (48\%). Referring to the above results, it can be concluded that smaller dosages of the molasses are more effective in retardation of the setting times; however, with subsequent increase in dosage, less retardation is detected; indeed, a reverse effect, i.e., acceleration, is obtained. Increasing the amount of molasses alternatively increases the amount of minor chemicals and chemical compounds such as chlorides and hydroxides, which are most known as accelerator admixtures. It is due to this phenomenon that a reverse effect was observed with respect to the increment of molasses dosage.

The research finding is conformed to other researches despite the dosage. The deviation was caused by the amount of sugar in the molasses. According to Juneja et al. [16], the maximum percentage increment of initial and final setting time was recorded as $94 \%$ and $43 \%$, respectively, by introducing a molasses having $20-25 \%$ sugar with dosage of $0.25 \%$ by weight of dry cement. Correspondingly, an approximately higher value of setting time 
Fig. 2 Percentage difference for setting time

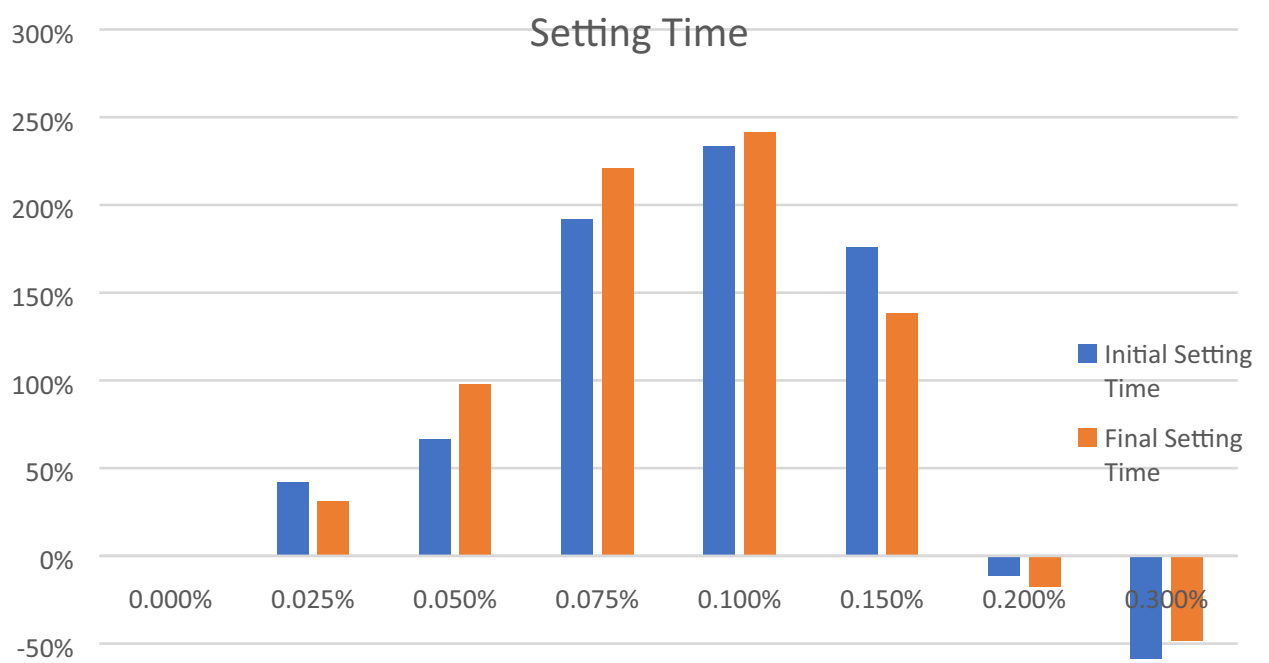

$-100 \%$ was observed in this research with $0.05 \%$ molasses dosage. Also, the observed negative effect due to the higher dosage is conformed to other researches.

Concrete specimens with molasses as admixture exhibited better workability than concrete without molasses. Based on the experimental results, as the percentage of molasses increased, consequently slump also increased. A true slump of $50 \mathrm{~mm}$ is observed with molasses percentage of $0.1 \%$ (see Fig. 3). Addition of molasses to the concrete greatly influenced its workability as witnessed during the experimentation, and this is due to the fact that molasses retardation mechanism is similar to common retarder admixture. According to the adsorption mechanism of retarder admixture, an impermeable layer will be developed on the cement particles. Due to the layer, water molecules are blocked to enter into the surface of anhydrate cement grains. As a result, slow hydration of cement occurs, which entails slowdown of the rate of strength development; in other words, the concrete mix remains plastic for certain time. This effect accounts for the record of higher slump value with respect to increment in the dosage of molasses.

Figure 4 shows the compressive strength development of the concrete samples together with the control sample for the 7, 14, and 28 days. The highest strength development throughout all its age was observed for concrete sample with molasses percentage of 0.1 by weight of cement; 25.4 MPa, 30.12 MPa, and 33.92 MPa were recorded for 7,14 , and 28 days, respectively. The molasses percentage of 0.05 and 0.075 by weight of cement shows an early compressive strength (7 days) below the reference; however, the 28 days strength shows a greater value than the reference. The relationship between the increase in 14 days compressive strength and dosage of molasses is almost linear. Also, the result was manifested until 28 days.

According to the finding of this study, it is evident that molasses can slow down the hydration reaction; in other words, it inhibits the chemical reaction, which contributes to strength development. Therefore, it is common to notice smaller strength development within 7 days.

Fig. 3 Concrete workability

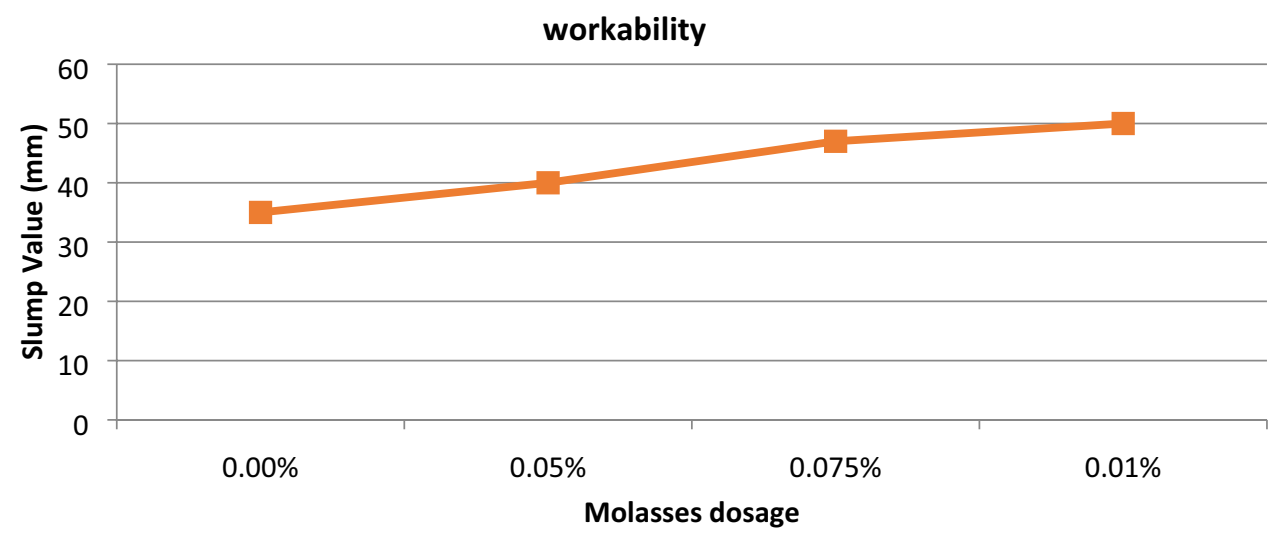


Fig. 4 Compressive strength test result

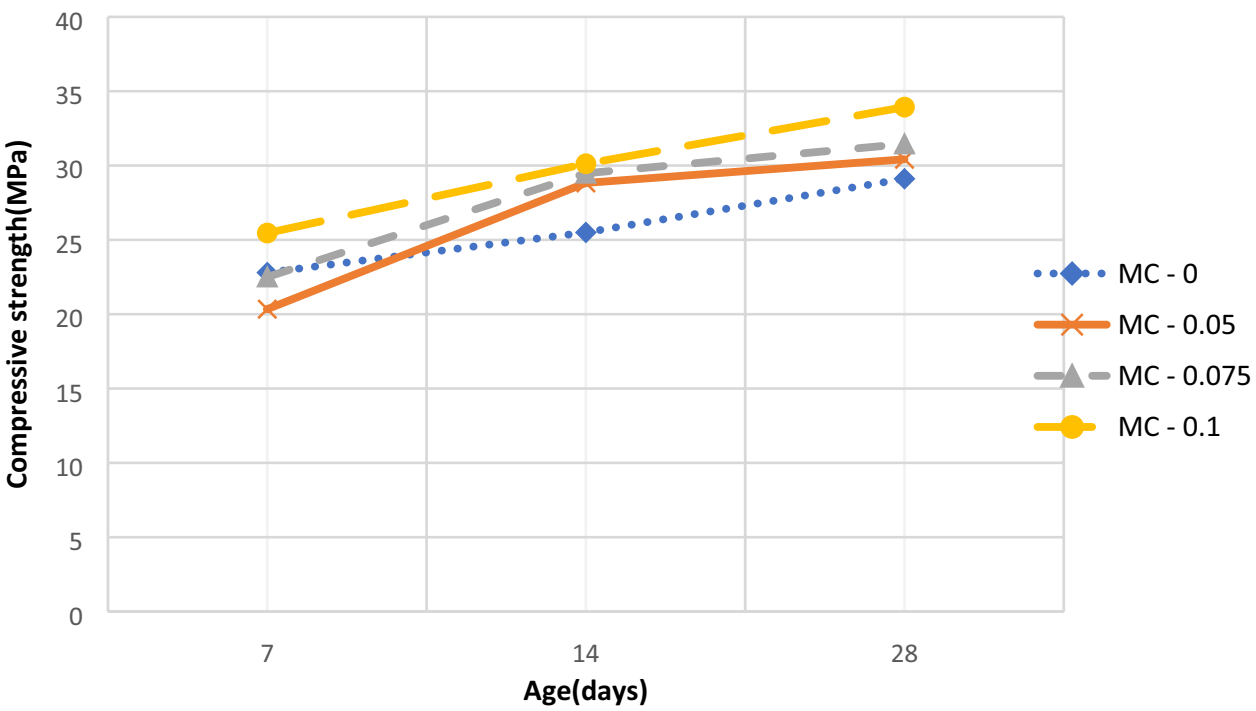

The positive effect on the development of compressive strength that observed on this study agrees with other research finding [21]. Also, it is conclusive to say that molasses enhance the compressive strength of concrete. However, further investigation is necessary to explain the nature of the hydration products, and the mechanism of interaction between cement and molasses contributes to strength increment.

\section{Conclusion}

The following conclusions are drawn based on the results of the present investigation:

(1) The presence of molasses into concrete has significantly improved the compressive strengths and setting time.

(2) The molasses dosage ranging from 0.05 to $0.075 \%$ gives a favorable maximum delay of initial setting time that complies with ASTM C494 specification. On the other hand, the molasses dosage ranging from 0.025 to $0.05 \%$ gives the appropriate final setting time.

(3) The workability of concrete containing molasses increases proportionally as the molasses percentage increases, which are due to the prolonged period of the stiffing process of concrete by molasses as a retarder admixture; thus, this could be exploited to reduce the amount of water to increase the compressive strength of concrete.

(4) Molasses-based cement paste with the dosage greater than $0.05 \%$ satisfies the ASTM C 494 specification for minimum compressive strength attainment of retarder admixture in 7 and 28 days, i.e., $90 \%$.
(5) The results of the experiment revealed that molasses has a capability to retard the setting time of cement paste, increase the workability, and reduce the strength development at the early ages. Therefore, molasses can be qualified as conventional retarder admixtures and can be used in hot weather concreting.

(6) However, some inconsistent result was observed due with increasing dosage, i.e., the opposite effect, accelerating the setting time. The finding of this research suggests that the dosage of $0.05 \%$ of molasses represents an optimum dosage.

(7) This research is limited to study the setting time of cement paste at room temperature; however, further studies are required to study at a different temperature as far as a varying degree of temperature produces a different effect of retardation.

Acknowledgements I want to express my sincere gratitude to Mr. Tewodros Kassa who was instrumental in providing me with the chance to complete this study, for his guidance and support at all times and his constructive criticism and advice during the preparation of this journal.

\section{Compliance with ethical standards}

Conflict of interest The authors declare that they have no conflict of interest.

\section{References}

1. Neville AM (2006) Concrete: Neville's insights and issues. Thomas Telford 
2. Ashworth $R$ (1965) Some investigations into the use of sugar as an admixture to concrete. In: Proceedings of the institution of Civil Engineers, London

3. Young JF (1972) A review of the mechanisms of set-retardation in Portland cement pastes containing organic admixtures. Cem Concr Res 2(4):415-433. https://doi.org/10.1016/00088846(72)90057-9

4. Thomas NL, Birchall JD (1983) The retarding action of sugars on cement hydration. Cem Concr Res 13(6):830-842. https://doi. org/10.1016/0008-8846(83)90084-4

5. Neville AM (1995) Properties of concrete, vol 4. Longman, London

6. SINTEF REPORT COIN P1 (2017) Advanced cementing materials SP 1.2 F Controlling hydration development retarding admixtures for concrete state of the art SINTEF Building and Infrastructure COIN-concrete innovation centre roar myrdal unrestricted 978-82-536-0998-0 3D006020 23 Electronic file code project manager (Harald Justnes) Checked by (Harald Justnes)

7. Suman R (2014) Effect of sugar on setting-time and compressive strength of ordinary Portland cement paste. In: 3rd world conference on applied sciences, engineering and technology, Kathmandu, Nepal, pp 27-29

8. Khan B, Baradan B (2002) The effect of sugar on setting-time of various types of cement. Sci Vis 8(1):71-78

9. Oyekan GL (2007) Effect of admixtures on the compressive strength of sandcrete blocks. University of Lagos, Lagos

10. Neville AM, Jeffrey JB (1987) Concrete technology. Longman Scientific and Technical, England

11. Francom MG, AG Counselor (2015) Ethiopia Ethiopia aims to become one of the world's top 10 sugar producers. $p 16$

12. Shimelis K, Ambachew D, Firehun G (2013) Trends of sugar industry development in Ethiopia: challenges and prospects. A paper presented on Ethiopian Science Academy conference, Addis Ababa, 28-30 November 2013

13. Berhane $Y$ (2015) Energy assessment, generation, and utilization efficiency in Ethiopian sugar factories. Addis Ababa University, Addis Ababa

14. Leo VC (1983) Molasses-general considerations. National Feed Ingredients Association, West Des Moines

15. Olbrich H (2006) The molasses. Kleinmachnow, Biotechnologie Kempe GmbH, p 131

16. Juneja A, Singh ER, Bhardwaj A, Kataria V (2017) To study accelerating and retarding behaviors of molasses in cement mortar and concrete. Int Res J Eng Technol 4(7):362-366
17. Somawanshi SP, Ansari US, Karale SA (2016) Effect of molasses in concrete as a water reducing and time retarding admixture. Int J Recent Sci Res 7(9):13417-13421

18. Yildirim H, Altun B (2012) Usage of molasses in concrete as a water reducing and retarding admixture. Indian J Eng Mater Sci 19(6):421-426

19. ASTM C494/C494 M-17 (2017) Standard specification for chemical admixtures for concrete. ASTM International, West Conshohocken

20. Elzamzami MA, Awad ME, Ali MOM (2000) The effect of molasses and VZ4 additions on the properties of cement paste and concrete. J Build Road Res 3(1):25-32

21. Akar C, Canbaz M (2016) Effect of molasses as an admixture on concrete durability. J Clean Prod. https://doi.org/10.1016/j.jclep ro.2015.09.081

22. M'Ndegwa JK (2016) Diversifying the use of molasses towards improving the infrastructure and economy of Kenya. Civil Environ Res 8(11):37-42

23. Pérez R (1995) Molasses. In: Tropical feeds and feeding systems, First FAO electronic conference

24. ASTM C187-16 (2016) Standard test method for amount of water required for normal consistency of hydraulic cement paste. ASTM International, West Conshohocken

25. ASTM C191-13 (2013) Standard test methods for time of setting of hydraulic cement by vicat needle. ASTM International, West Conshohocken

26. ASTM C143/C143 M-10a (2010) Standard test method for slump of hydraulic-cement concrete. ASTM International, West Conshohocken

27. Ethiopian Building Code Standard, Structural Use of Concrete. EBCS-2. Ministry of Work and Urban Development, Addis Ababa, Ethiopia, 1995

28. IS:516 (1959) Method of test for strength of concrete. ISI, Manak Bhavan, New Delhi

Publisher's Note Springer Nature remains neutral with regard to jurisdictional claims in published maps and institutional affiliations. 